Slavica

bruxellensia

\section{Slavica bruxellensia}

Revue polyphonique de littérature, culture et histoire

slaves

$2 \mid 2009$

Femme(s)

\title{
Lenka Procházková, Slunce v ùplňku (Přiběh Jana Palacha)
}

\section{Richard Vacula}

\section{OpenEdition}

\section{Journals}

Édition électronique

URL : http://journals.openedition.org/slavica/184

DOI : $10.4000 /$ slavica. 184

ISSN : 2034-6395

\section{Éditeur}

Université libre de Bruxelles - ULB

\section{Édition imprimée}

Pagination : 69-70

ISSN : 2031-7654

Référence électronique

Richard Vacula, "Lenka Procházková, Slunce v ùplňku (Přiběh Jana Palacha) », Slavica bruxellensia [En ligne], 2 | 2009, mis en ligne le 15 février 2009, consulté le 22 septembre 2020. URL : http:// journals.openedition.org/slavica/184; DOI : https://doi.org/10.4000/slavica.184

Ce document a été généré automatiquement le 22 septembre 2020

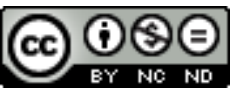

Les contenus de Slavica bruxellensia sont mis à disposition selon les termes de la Licence Creative Commons Attribution - Pas d'Utilisation Commerciale - Pas de Modification 3.0 France. 


\section{Lenka Procházková, Slunce v ùplňku (Přiběh Jana Palacha)}

Richard Vacula

RÉFÉRENCE

Lenka Procházková, Slunce v ùplňku (Přiběh Jana Palacha), Prostor, Prague, 2008, 288 p. 
Lorsque Lenka Procházková publia son roman Slunce vúplňku (Plein soleil) en 2008, le thème n'était pas nouveau pour elle. En effet, en 1988 elle avait rédigé un texte sur le sacrifice de Jan Palach, l'étudiant tchèque qui, en janvier 1969, s'immola à Prague pour protester contre l'occupation de la Tchécoslovaquie par les armées du Pacte de Varsovie. Ce texte ne vit alors le jour que sous la forme d'un samizdat. L'auteur a décidé de reprendre et de modifier son texte.

Dans son roman, Procházková opte pour une langue vive et simple, un grand nombre de dialogues et une construction chronologique du texte. Ainsi, elle élabore un récit qui se lit facilement et immerge puissamment le lecteur dans l'histoire racontée. De surcroît, l'auteur arrive à conserver une impression de témoignage documentaire en alternant des chapitres purement romanesques (écrits à la $3^{\mathrm{e}}$ personne du singulier) et des extraits de journal intime imaginés (à la $1^{\text {ère }}$ personne).

L'histoire du roman est encadrée par deux dates clés : le 21 août 1968, jour de l'invasion des armées du Pacte de Varsovie, et le 19 janvier 1969, jour de la mort de Palach. Ces cinq mois qui séparent ces deux dates ont modifié le destin de la Tchécoslovaquie, alors en voie de démocratisation, et sont relatés à travers les yeux d'un étudiant. Néanmoins, Procházková ne s'intéresse pas tant aux faits historiques qu'aux humeurs qui traversaient progressivement la société : l'esprit militant, le scepticisme et l'apathie généralisée, contre laquelle Palach voulait précisément lutter.

Ce roman représente sans doute plus qu'une simple chronique ou une analyse des motifs qui ont abouti à cette immolation. C'est tout d'abord le témoignage authentique d'un membre de cette génération "perdue » : Procházková est née deux ans et demi après Palach. Ce roman est surtout une tentative artistique de s'acquitter de la dette qu'une grande partie des étudiants de l'époque ressentait à l'égard de leur collègue qui s'était résolu à agir.

Enfin, il s'agit également d'honorer son dû à l'histoire elle-même: Procházková constate, par l'intermédiaire des personnages de son roman, que l'expérience vécue reste intransmissible. Avec la responsabilité et la grâce d'un écrivain expérimenté, elle semble nous indiquer qu'il est un devoir d'agir comme témoins des moments importants de l'Histoire. Tout le récit est pénétré par le goût intensif de cette époque, par son toucher de l'incommunicable, par l'essence de l'expérience personnelle, des espérances et désillusions profondes, que l'auteur incorpore dans son roman.

Le récit est suivi d'une postface où Procházková explique le contexte de création de son roman, cite quelques témoignages authentiques, reprend l'intégralité du Manifeste des 
deux mille mots, rédigé par Ludvík Vaculík, et joint quelques photographies de l'invasion et de l'enterrement de Palach.

7 Le roman Slunce $v$ úplňku représente une action artistique remarquable et spécifique dans le contexte de l'histoire contemporaine des pays de l'Europe Centrale. Sorte d'épopée héroïque moderne, il constitue le premier texte littéraire traitant avec succès du rôle des étudiants dans les événements de 1968 en Tchécoslovaquie.

INDEX

Index chronologique : communisme, XXe siècle

Mots-clés : histoire tchèque, littérature tchèque

Index géographique : Tchécoslovaquie

\section{AUTEURS}

RICHARD VACULA

Université Charles de Prague, Université Libre de Bruxelles 